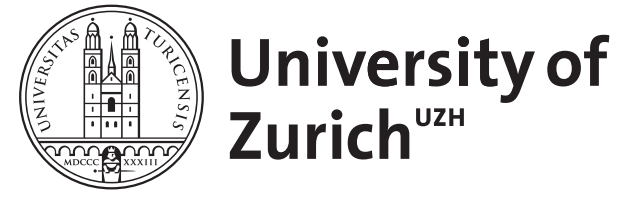

\title{
Nonsense Made Intelligible
}

\author{
Glock, Hans-Johann
}

\begin{abstract}
My topic is the relation between nonsense and (un-)intelligibility, and the contrast between nonsense and falsehood which played a pivotal role in the rise of analytic philosophy (sct. 1). I shall pursue three lines of inquiry. First I shall briefly consider the positive case, namely linguistic understanding (sct. 2). Secondly, I shall consider the negative case - different breakdowns of understanding and connected forms of failure to make sense (sct. 3-4). Third, I shall criticize three important misconceptions of nonsense and unintelligibility: the austere conception of nonsense propounded by the New Wittgensteinians (scts. 5-6); the "no nonsense position" which roundly denies that there are cases of nonsense - Chomsky's semantic anomalies or Ryle's category mistakes-that are grammatically well-formed, without even having the potential for being used to make a truth-apt statement (scts. 7-8); the individualistic conception of language and of semantic mistakes championed by Davidson (scts. 9-10). All three positions, I shall argue, ignore or deny combinatorial nonsense, the fact that perfectly meaningful sentence-components can be combined in a way that may be grammatical, yet without resulting in a sentence that is itself "meaningful", i.e. endowed with linguistic sense. At a more strategic level, the first and the third position deny or ignore that natural languages are communal historical practices that go beyond idiolects and the employments of expressions in specific contexts and that are guided by semantic rules - standards for the meaningful use of words.
\end{abstract}

DOI: https://doi.org/10.1007/s10670-014-9662-5

Posted at the Zurich Open Repository and Archive, University of Zurich

ZORA URL: https://doi.org/10.5167/uzh-207588

Journal Article

Published Version

Originally published at:

Glock, Hans-Johann (2015). Nonsense Made Intelligible. Erkenntnis, 80(S1):111-136.

DOI: https://doi.org/10.1007/s10670-014-9662-5 


\title{
Nonsense Made Intelligible
}

\author{
Hans-Johann Glock
}

Received: 12 August 2014/ Accepted: 12 August 2014/Published online: 19 September 2014

(C) Springer Science+Business Media Dordrecht 2014

\begin{abstract}
My topic is the relation between nonsense and (un-)intelligibility, and the contrast between nonsense and falsehood which played a pivotal role in the rise of analytic philosophy (sct. 1). I shall pursue three lines of inquiry. First I shall briefly consider the positive case, namely linguistic understanding (sct. 2). Secondly, I shall consider the negative case-different breakdowns of understanding and connected forms of failure to make sense (sct. 3-4). Third, I shall criticize three important misconceptions of nonsense and unintelligibility: the austere conception of nonsense propounded by the New Wittgensteinians (scts. 5-6); the "no nonsense position" which roundly denies that there are cases of nonsense-Chomsky's semantic anomalies or Ryle's category mistakes-that are grammatically wellformed, without even having the potential for being used to make a truth-apt statement (scts. 7-8); the individualistic conception of language and of semantic mistakes championed by Davidson (scts. 9-10). All three positions, I shall argue, ignore or deny combinatorial nonsense, the fact that perfectly meaningful sentencecomponents can be combined in a way that may be grammatical, yet without resulting in a sentence that is itself "meaningful", i.e. endowed with linguistic sense. At a more strategic level, the first and the third position deny or ignore that natural languages are communal historical practices that go beyond idiolects and the employments of expressions in specific contexts and that are guided by semantic rules - standards for the meaningful use of words.
\end{abstract}

The philosopher's proprietary question is not "What does this or that expression mean?", but "Why does this or that expression make nonsense? and what sort of nonsense does it make?".

$$
\text { Ryle (1970, pp. 6-7). }
$$

\section{H.-J. Glock ( $\bowtie)$}

Philosophisches Seminar, Universität Zürich, Zürichbergstrasse 43, 8044 Zurich, Switzerland e-mail: glock@philos.uzh.ch 


\section{An Underappreciated Contrast}

My topic is the relation between nonsense and (un-)intelligibility. The contrast between nonsense and falsehood played a pivotal role in the rise of analytic philosophy. It has been unduly neglected since the 1970s, but has recently been revived. The sources of this renewed interest are twofold. The topic of nonsense occupies centre stage in current debates sparked by the self-styled "New Wittgensteinians". More importantly, mainstream analytic philosophy has come to appreciate the importance of the metaphilosophical issues that were such a striking feature of its early career. These issues include the question of whether one central task of philosophy is the diagnosis and avoidance of certain forms of nonsense.

The contrast I have in mind runs as follows. Some grammatically well-formed sentences in the indicative and/or their use in assertoric speech-acts are neither false nor unjustified or unwarranted. Instead, they apparently suffer from a more basic defect, a defect of a semantic kind. They are neither true, nor even false, but fail to be truth-apt. Mutatis mutandis for questions. At least some traditional philosophical questions do not call for an answer, but need in turn to be questioned, since they make no sense (see Moore 1903, p. vi).

Failure of truth-aptness is clearly distinct from falsehood. But at least two distinct failures have been identified. For one thing, there are the truth-value gaps famously detected by Frege and Strawson. According to them, some meaningful assertoric sentences are neither true nor false. More accurately, by using them on a particular occasion, a speaker does not express a truth-apt proposition or statement. The rationale is that at least one of their singular terms lacks a determinate reference, since there is no unique referent for its use on this occasion. Either there is no referent at all, or there is more than one. The most famous example is, of course, "The present king of France is bald".

The second type of failure of truth-aptness is lack of sense. It featured in Frege and Russell, yet it really came into its own through Wittgenstein, Carnap and Ryle. Some grammatically well-formed sentences cannot be used to make a truth-apt assertion for purely linguistic reasons, independently of the contingent satisfaction of existence and uniqueness conditions pertaining to their constituent singular terms. These sentences appear to be meaningless, senseless or nonsensical. By the same token, it would appear that they defy linguistic understanding, i.e. are unintelligible to competent speakers, by contrast to the aforementioned truth-value gaps. Potential candidates for this second type of failure include: "There is Julius Caesar" (Frege); "The class of barbers is a member of itself" (Russell); "This inkblot has been fiddled down on a piano" (Meinong); "The table penholders the book"; "Socrates is identical" (early Wittgenstein); "This stone is thinking of Vienna"; "Quadruplicity drinks procrastination"; "Caesar is a prime number" (Carnap); "White is darker than black" (later Wittgenstein); "Colourless green ideas sleep furiously" (Chomsky). ${ }^{1}$

\footnotetext{
${ }^{1}$ Chomsky (1957, p. 15) treats this "semantic anomaly" as grammatical yet nonseniscal. By contrast, Chomsky (1965) contests the idea that such sentences are syntactically well-formed.
} 
In order to shed light on the connection between nonsense and unintelligibility, I shall pursue three lines of inquiry. First I shall briefly consider the positive case, namely linguistic understanding (sct. 2). Secondly, I shall consider the negative case-different breakdowns of understanding and connected forms of failure to make sense (sct. 3-4). Third, I shall criticize three important misconceptions of nonsense and unintelligibility:

- the austere conception of nonsense propounded by the New Wittgensteinians (scts. 5-6);

- the "no nonsense position" which roundly denies that there are cases of nonsense-Chomsky's semantic anomalies or Ryle's category mistakes-that are grammatically well-formed, without even having the potential for being used to make a truth-apt statement (scts. 7-8);

- the individualistic conception of language and of semantic mistakes championed by Davidson (scts. 9-10).

All three positions, I shall argue, ignore or deny combinatorial nonsense, the fact that perfectly meaningful sentence-components can be combined in a way that may be grammatical, yet without resulting in a sentence that is itself "meaningful", i.e. endowed with linguistic sense. At a more strategic level, the first and the third position deny or ignore that natural languages are

i. communal historical practices that go beyond idiolects and the employments of expressions in specific contexts;

ii. guided by, among other things, semantic rules — standards for the meaningful use of words.

\section{Intelligibility and Understanding}

My ambition is to account for unintelligibility. Yet what requires explanation from both lay and scientific perspectives is not unintelligibility or failure of understanding; it is rather the very phenomena of intelligibility, linguistic sense and understanding. At present, for instance, there is an mushrooming interest in explaining the genesis of natural languages with full-blown syntactic and semantic systematicity and productivity. For better or worse, however, philosophers have always been more puzzled by the possibility of failure-falsehood, error, irrationality, weakness of will, evil, etc.-than of success (a kind of Murphy's law in reverse). Still, in order to get a grip on failure, it behoves us to have a look at success-i.e. linguistic understanding.

Concerning this topic, I adopt a Wittgensteinian perspective that I have defended elsewhere (Glock 1996). First, understanding is not a mental or neural act or process accompanying linguistic communication. As far as our extant concept is concerned, mental or physiological goings on are neither necessary nor sufficient for understanding. While neurophysiological processes are causal preconditions of 
understanding, they do not constitute understanding, as understood by laypeople and even most philosophers and scientists. Secondly, understanding is a (mental) state only in a minimal grammatical sense: it is signified by a static verb. That is to say, "to understand" lacks imperatival and participle I (continuous) forms, and it cannot be combined with all adverbs of modality. Nonetheless there is a contrast to genuine mental states like having a headache or being sad. Understanding lacks genuine duration: one cannot ascertain by checking introspectively whether it still obtains, and it is not interrupted, e.g., by sleep. Finally, there are no criteria for being in this state which are independent of its manifestations. There is no conceptual connection, for instance, between a certain neurophysiological state and understanding a linguistic expression or utterance. But there are conceptual connections between understanding and what speakers and hearers do or are capable of doing.

This strongly suggests that understanding is a potentiality rather than an actuality, in Aristotelian terminology. At the same time, understanding is not a disposition either in the technical sense introduced by Carnap or in the everyday sense of character traits. For I do not avow linguistic understanding on the basis of observing my past behaviour under similar circumstances. Nevertheless, understanding an expression is akin to an ability. Typical abilities of human beings are what Kenny calls "two-way powers". Unlike "one-way" or "natural powers", these two-way powers are not automatically exercised given certain antecedent conditions. Rather, their possessors can exercise them or refrain from exercising them at will, in the most explicit case through a decision. Greenhouse gases have the power to trap light reflected from the surface, and will inevitably do so given certain conditions. By contrast, I can choose whether or not to exercise my ability to cycle to work. Now, linguistic understanding is not (uniformly) subject to the will. I can refrain from exercising my linguistic understanding actively, by employing an expression in an utterance. As Kenny points out, however, passive understanding is not subject to the will: "Looking up at the flashing lights of the advertisements in Piccadilly Circus, one cannot prevent oneself from understanding their message. (How much more beautiful they would be, G. K. Chesterton once remarked, if only one could not read!)" (Kenny 1989, p. 22; see also Baker and Hacker 2005, ch. XVII. 4).

However, it does not follow that understanding is a one-way power. We need to heed the difference between the understanding of type expressions, which constitutes lexical or semantic competence in a language, and the understanding of token expressions uttered in a specific context. It is prima facie plausible to regard the first as "dispositional" — a kind of potentiality-and the second as "occurrent", an event, process or action that happens at a particular time, as does Dummett (1991, pp. 274-275). Yet this claim fails to take account of another distinction between two types of potentiality, namely first- and second-order powers. Second-order powers are powers to acquire first-order powers. A person may have the first-order power-especially the cardio-vascular fitness-to run a marathon under three hours, without ever actually doing so. But a person may also 
have the second-order power-roughly the physique and mental strength-to acquire that first-order power, even if she never trains hard enough actually to acquire it. ${ }^{2}$

Kenny's observation is correct as regards the passive aspects of lexical competence vis-à-vis type expressions. This is indeed a one-way power. Its exercise or manifestation on the occasion of encountering a token expression is not subject to the will. And Dummett is right in so far as this exercise is indeed something that happens at a particular time-by contrast to the acquisition of lexical competence. In most cases, however, it is not so much occurrent as episodic. When a competent speaker hears a straightforward utterance, there is normally no process of understanding that lasts over a period of time. I understood Obama's utterance "Yes we can!" the moment I heard it on the radio. Nevertheless, even such instantaneous understanding is a datable event. Normally that event is concurrent with hearing the utterance; but in more challenging cases (of which more below) it may occur subsequently, sometimes as the result of a genuine process.

But now, what is this datable event? It is tempting to hold, with Dummett, that it is the understanding of the token expression, and that the latter is simply an actual mental going-on rather than a potentiality. This conclusion falls short. For what constitutes having understood the token expression at a particular time? Nothing in the hearer's mental or neurophysiological life that lies open to introspection by the hearer or even by God. It is rather what the hearer is capable of doing (see Glock and Preston 1995). This implies that the understanding of a token expression is not just the manifestation of a second-order potentiality, but that it must in turn be conceived in terms of a first-order potentiality.

In fact, there are two ways of spelling out this idea. The first accepts that the manifestation of lexical competence-the datable episode-is the understanding of the token expression. But what happens on such an occasion is itself an achievement in Ryle's sense. ${ }^{3}$ That achievement consists in having acquired a first-order power. On this construal, the manifestation of the second-order power simply is the firstorder power, contrary to the standard explanation according to which it is the acquisition of such a power.

However, there is an alternative which sticks to that formula. What happens when a competent speaker hears a straightforward utterance is not itself the understanding of the token expression, but the acquisition of such understanding. One might also speak of the coming to understand, except that this intimates an enduring process even in cases of instantaneous understanding. In ordinary parlance, we often speak of understanding and related cognitive achievements when in fact we mean coming to understand. This version also does justice the fact that we do not just speak of my having understood Obama's by now notorious slogan in 2008, but

\footnotetext{
${ }^{2}$ For the distinction between first- and second-order powers see Kenny (1989, p. 20) and Hacker (2006, pp. 105-106).

3 See Rundle (2001, pp. 109-110), Baker and Hacker (2005, pp. 381-382). Even this variant of my account differs from theirs, however, by conceding the episodic nature of token understanding and by employing the dichotomies between first- and second-order powers and between one-way and two-way powers.
} 
of (still) understanding it now. That understanding is not a genuine process or state with genuine duration. I haven't been in a state of understanding the slogan since then, and my understanding it neither lasted through periods of sleep nor was it interrupted by them. It is a power in the sense explained above, a first-order power acquired through the manifestation of a second-order power on the occasion of first hearing the utterance.

On either construal, what happens when a competent hearer understands an utterance - the coming to understand the token expression-is the acquisitionwhether concurrent or subsequent, whether instantaneous or gradual-of a power. And that power is indeed a two-way power or ability. For its constitutive of that power that it manifests itself in two ways:

(a) responding appropriately to the utterance;

(b) correctly explaining the utterance or token expression, notably through paraphrase.

And these manifestations or exercises of the power are subject to the will. The same goes for the constitutive manifestation of active lexical understanding, which is

(c) employing expressions appropriately.

In short, active lexical understanding of type expressions is a first-order two-way power exercised by using and explaining the term correctly. Passive lexical understanding of type expressions is a second-order one-way power. It is exercised or manifested by (acquiring an) understanding of a token expression uttered in a particular situation. For its part, that understanding is a first-order two-way power exercised by reacting fittingly to the utterance and by explaining it adequately.

Note, that even passive lexical understanding differs from other one-way powers in one important respect. Unlike mere physical dispositions, but like active lexical understanding and token understanding, its exercise is subject to normative assessment. And such assessment goes beyond the evaluation according to presumed teleological standards like maximizing biological fitness of which the subject being assessed may be completely ignorant. How tokens of a type are used in general by a speaker allows of justification, criticism and correction; and so does how a particular token is understood by a hearer on a particular occasion. But even the way a hearer understands tokens of a type in general can be defended, criticized and rectified. The reason is that we expect normal members of a linguistic community to acquire lexical understanding, in both its active and passive capacity. This intermediate status is further confirmed by the fact that understanding is linked to abilities which are two-way powers. 
In the Aristotelian tradition as developed by Thomas Aquinas, knowledge in general is understood as the meeting point of two potentialities: the potentiality of the subject to cognize, and the potentiality of the object to be cognized. This model is not trivial, since "object" need not be understood ab initio as object of a possible cognition. Still, one might object that every actualization of a potentiality can be conceived as the convergence of two potentialities. For instance, isn't the actualization of my capacity to swim at the same time an actualization of the water's capacity to be swum in? However, the contrived air of that formulation immediately points towards a shortcoming in that proposal. The Thomist model is appropriate in cases in which a potentiality or power has a bona fide suitable object towards which the power is directed. This may hold for all or many cognitive capacities, but not for swimming. Instead, water or its presence should be conceived as external opportunity conditions for the exercise of my power to swim rather than as the latter's objects. ${ }^{4}$

At the same time, the objection draws attention to a weakness of the Thomist picture. While the latter need not define the world and its constituent phenomena as possible objects of cognition, it is committed to the idea that these phenomena are essentially suitable objects of human cognition. It is essential to water, for instance, that we are in principle capable of cognizing it, whereas it is not essential to water that it affords the opportunity for swimming. This makes perfect sense given the idea that God created the world among other things for the purpose of being cognized by human beings. Without that assumption, however, this model is more apposite with respect to linguistic understanding. For language is the kind of artefact that the world is according to theism. First, type expressions are constitutive parts of practices (natural languages) that serve a bona fide function, namely that of communication. Secondly, tokens of these types are standardly uttered by speakers with an intention, namely the intention of being understood. As a result of these features, the Thomist picture of knowledge or comprehension in general nicely fits linguistic understanding. The latter is the convergence of two potentialities-the hearer's capacity to understand and the utterance's capacity to be understood, i.e. its intelligibility.

\section{Different Breakdowns of Understanding}

This convergence is subject to different kinds of breakdown, usually for worse, but sometimes for better. Here are manifestations of different failures of linguistic understanding:

(1) I cannot understand you, you must speak louder

(2) I heard her loud and clear, but couldn't make out what language she was speaking

\footnotetext{
4 The distinction between a power, its exercise and the opportunity conditions for that exercise hails from Kenny, e.g. (1989, ch. 5).
} 
(3) I cannot understand you, I don't speak Spanish

(4) I cannot understand this, it is garbled

(5) I cannot understand you, that is sheer nonsense

(6) I understand the words, but not what they mean in this context

(7) I understand what the words mean, but not to what or whom your refer

(8) I understand what you said, but not whether it was a threat or a promise

(9) I understand what you said, but don't see the joke (but not what you are driving at)

(10) I understand what you said, but not what the implications are

(11) I understand the words of this poem, but not what it means. ${ }^{5}$

These different breakdowns of understanding correspond to different types of understanding. Just like "making sense", "being unintelligible" and "understanding" have "different senses in different cases" (Wittgenstein 1993, pp. 66-67). We can distinguish at least the following degrees of understanding, which amount to an overcoming of the respective breakdowns listed above.

Ad (1) Accurate perception: This is achieved once we have discerned the uninterpreted acoustic or typographic token, which has not even been assigned yet to a particular language. If we have understood perceptually, we won't need to say things like (1). Even sounds that do not belong to any language whatever can satisfy this requirement.

Ad (2) Recognition of a language: This is something that we can do as soon as we identify the language from which the utterance hails, without necessarily understanding the utterance or any of its component words.

Ad (3) Recognition of words: We can do this with any sequence of expressions that we understand individually, even if that sequence fails to constitute a wellformed sentence. Once this is possible, we can also translate the sequence, at least into languages with a similar morphology.

Ad (4) Recognition of a sentence structure: this is possible in the case of the semantic anomalies devised by Chomsky. Because of their syntactic structure, we can report such sentences not just in direct speech, but also in indirect speech. We can answer questions as to case, tense, and number. Where appropriate, we can transform such sentences from the active into the passive voice and vice versa. We can specify particular rules that have been violated. By the same token, in some cases, such as "Augustine is my favourite paint" we can conjecture that they result from a (typographic or acoustic) slip rather than from syntactic or semantic confusion.

Ad (5) Understanding of potential sense: This is the understanding competent speakers have of any syntactically well-formed and meaningful type-sentence. Anglophones perfectly well understand e.g. "Old men and women went to the bank". What they require to understand a token-utterance of such sentences is not linguistic instruction, but disambiguation of lexical and structural ambiguities.

\footnotetext{
5 Several items on this list hail from Waismann (1965, p. 347). Others combine Wittgensteinian ideas with more recent distinctions (drawn in Künne 1983, pp. 196-202).
} 
Ad (6) Understanding of actualised sense: This is achieved on removal of such ambiguities, e.g. once we are told that the utterance means that old men and old women went to the river bank.

Ad (7) Understanding of what is said: Such understanding differs from the understanding of actualised sense in the case of indexical utterances like "You've lost something" or "Today is Monday". What we need to know here concerns not the sense of the type-sentence, but the conditions of utterance of specific tokens.

Ad (8) Understanding of illocutionary force: We may understand what is said by Arnold Schwarzenegger's "I'll be back" in Terminator, without yet knowing what kind of speech act it is, whether it is, for example, a conversational flourish, a prediction, a promise or a threat.

Ad (9) Understanding of conversational implicatures: This kind of understanding is absent in the case of the novice academic who fails to spot that in a reference for a $\mathrm{Ph} . \mathrm{D}$. candidate the sentence "He turns his essays in on time" does not count as a recommendation. Such a novice might for example say to the referee "I don't see why you write...". Unlike (8), this failure does not involve general linguistic conventions of the kind highlighted in speech act theory, but features of a specific kind of situation.

Ad (10) Understanding of implications: Holistic thinkers have maintained, implied or intimated that one cannot understand a sentence, or entertain the thought it expresses, without understanding all of its logical or conceptual implications. In my view, this is an exaggeration. Someone can understand a statement, at least up to a certain point, without understanding all of its indefinitely many consequences (Glock 2003, pp. 281-286). Nevertheless, grasping the pertinent implications of a statement constitutes a distinct level of understanding.

Ad (11) Aesthetic Understanding: One basic criterion for understanding a linguistic expression noted above is the ability to explain or paraphrase it. As Wittgenstein pointed out, however, this ability does not suffice for understanding a work of art (1967, §§522-535). For example, someone who understands a poem will not just be able to paraphrase the expressions occurring in it, she will also be able to indicate why some of them cannot be replaced by a paraphrase in this context. In this respect, understanding a poem involves a higher degree not just of artistic appreciation but also of linguistic understanding.

\section{Different Types of Nonsense}

As mentioned above, a philosophically interesting type of failure of linguistic understanding or unintelligibility results from lack of sense or from nonsense. Here perceptual understanding is taken for granted and questions of understanding potential and actualized sense, utterance content, illocutionary force, conversational implicatures, etc. do not arise. But it is imperative to note that in ordinary parlance no less than in linguistics and philosophy, "senseless", "nonsensical" and their cognates can mean at least three different things. In one sense, they apply to statements or beliefs and mean something like patently false or unreasonable (we tend to label such cases "nonsensical" more often than "senseless"). In this 
capacity, the term was widely used in the enlightenment, to brand superstition and religious dogma. At present, it is popular among politicians, especially when it comes to disparaging uncomfortable allegations as "absolute and utter nonsense". I shall refer to this as absurdity.

In a second sense, the term applies to actions of all sorts, including linguistic utterances, and means something like obviously pointless or futile. I shall refer to this as futility (here we prefer to speak of "senseless" rather than "nonsense"). Both usages retain a connection to the original meaning of the German Unsinn, in that a nonsensical statement or action betokens lack of sense or even sanity. In a third and historically most recent sense, our terms apply to linguistic expressions or utterances and mean something like meaningless or unintelligible. I shall refer to this as linguistic nonsense or simply as nonsense.

Now consider various candidates for linguistic nonsense:

(12) Ab sur ah

(13) The was it blues no

(14) Socrates is identical

(15) Julius Caesar is a prime number

(16) Colourless green ideas sleep furiously

(17) Moscow lies northeast of the South Pole

(18) $\sqrt{ } 2 \in \mathrm{Z}$

(19) White is darker than black

(20) You can't step into the same river twice

An utterance of (12) may invite a reaction like (2), notwithstanding the fact that in this case there is no language to be specified in response, and an utterance of (13) a reply like (4). (12)-(16) all standardly provoke a reaction like (5). In the wake of Ryle (1949, 1971, ch. 12), cases like (15)-(16) have been labelled "category mistakes". They predicate of one kind of thing what can only be predicated of another kind; more generally, there is a mismatch between subject and predicate, a characterization that fits (14) as well. Some of the other statements may not be classified as nonsense immediately, but instead be treated as absurd. (17)-(20) are necessary falsehoods that contradict necessary truths of certain conceptual schemes, for instance the way we individuate rivers in the case of a metaphysical pronouncement like (20). Elsewhere I have defended Wittgenstein's controversial claim that necessary falsehoods are nonsensical, on the grounds that, like category mistakes, they defy coherent explanation of what would have to be the case for them to be true (Glock 2008). In this article I shall discuss the very idea of combinatorial nonsense, which Wittgenstein shares not just with an otherwise disparate group of philosophers like Husserl, Carnap and Ryle, but also with common sense. Certain types of nonsense-notably (14) to (17)-result from sentence components (words) that are themselves meaningful (in a language) being combined in a way that is syntactically licit (at least prima facie), yet semantically unsound.

This idea has been challenged more or less explicitly by the New Wittgensteinians, on the one hand, and the no nonsense position on the other. It is also ruled out 
by Davidson's construal of semantic infelicities. I shall confront these challenges in turn.

\section{Combinatorial Nonsense and Contextualism}

The New Wittgensteinians contend that Wittgenstein's conception of nonsense, both early and late, rules out combinatorial nonsense. I have criticized this interpretation elsewhere (Glock 2004), and will leave exegetical issues aside here. Instead I shall tackle the substantive merits of the conception of nonsense that the New Wittgensteinians do not just attribute to Wittgenstein but also wholeheartedly condone. They characterize it as "austere" rather than "substantial" (Creary and Read 2000, pp. 12-13; Diamond 1991: pp. 111-112; 2000: pp. 153, 165; Conant 2002 , pp. 380-383). There are two aspects to this contrast. First, according to the austere conception, nonsense is always a matter of privation. Whereas the substantial conception allows for "positive nonsense", nonsense that results from combining meaningful expressions in illegitimate ways, the austere view allows only for "negative nonsense", nonsense which results from our not having assigned a meaning to expressions in a certain context. Secondly, the austere conception of linguistic nonsense is monistic. Whereas the substantial conception distinguishes between different types of nonsense, the austere view insists that from a philosophical or logical point of view there is only one kind of nonsense: "all nonsense is just nonsense" (Diamond 2000, p. 165); logically or semantically speaking there is no difference between the statements of metaphysicians and the babblings of a drunkard.

Nonsense monism and the exclusion of combinatorial nonsense seem to follow from the privation thesis: there is just one type of nonsense, since all nonsense is negative, a consequence of privation. In fact, however, even if all nonsense were a matter of not having given sense to a particular string of words, one could still distinguish between meaningless strings of words which fulfil the following condition, and those which do not: For every word "w" in (the meaningless sentence) $* s$ there is a meaningful sentence containing "w". By the same token, one could provide a definition of "combinatorial nonsense" compatible with the privation thesis:

$*_{s}$ is combinatorial nonsense if and only if

(i) $*_{s}$ is a sentence (in the purely grammatical sense);

(ii) $*_{s}$ is meaningless;

(iii) For every word „W“ in $*_{s}$ there are meaningful sentences containing „W“.

This definition is perfectly compatible with the idea that fulfilling condition (ii) is inevitably a matter of privation, of a failure to assign a meaning to " $\mathrm{S}$ ". The only issue, it would appear, is whether or not meaningless sentences fulfilling conditions (i) and (ii) should be labelled "combinatorial nonsense". 
That question is to be answered in the affirmative, since this attempt to stake out a different type of nonsense appeals to what can be done with the components of meaningless sentences in other contexts. Yet that is precisely an idea that proponents of the austere conception have disregarded more or less explicitly (see sct. 6).

That this policy won't wash is illustrated by considering the arguments in favour of the privation thesis. At least implicitly, these arguments take the following form:

$\mathrm{P}_{1} \quad \mathrm{~A}$ word (name) has meaning only in the context of a proposition (context principle, "restrictive" version)

$\mathrm{P}_{2} \quad$ A proposition is a sentence with a sense (by definition)

C No component of a sequence of signs that lacks a sense can have a meaning.

$\mathrm{P}_{2}$ employs the notion of a proposition in a strong sense. A proposition is not just a sequence of uninterpreted sounds or inscriptions-but one that is used, paradigmatically to say something that is true or false. In the idiom of the Tractatus, a proposition is a symbol rather than a mere sign. Given this understanding, $\mathrm{C}$ indeed follows. For a sequence of signs that lacks sense does not constitute a proposition and hence, on account of $\mathrm{P}_{1}$, its components do not satisfy a precondition for having a meaning. $\mathrm{C}$ rules out combinatorial nonsense and hence implies the privation thesis. And the argument in its favour is valid. But is it sound?

The answer to this question turns on $\mathrm{P}_{1}$. The latter amounts to a restrictive form of contextualism (for different forms of contextualism, see also Baker and Hacker 2005, ch. IX). In the wake of Frege and Wittgenstein, $P_{1}$ has been repeated by countless philosophers, Quine and Davidson pre-eminent among them. Nevertheless, it has one major shortcoming: it is wrong!

Consider the following two columns:

\begin{tabular}{ll}
\hline to be & to abide \\
to have & to arise \\
to do & to awake
\end{tabular}

Two things about these words are indisputable. First, they are not part of a proposition. Secondly, they are neither meaningless nor nonsensical, but $d o$ have a meaning. The words in the first column are the auxiliary verbs of English, the words in the second are the first three items from the dreaded list of irregular English verbs.

Next consider the following extract from the Merriam Webster's Collegiate Dictionary:

nonsense $n 1$ a: words or language having no meaning or conveying no intelligible ideas $b$ (1): language, conduct, or an idea that is absurd or contrary to good sense (2): an instance of absurd action 2 a: things of no importance or value: trifles b: affected or impudent conduct 
One might make out a case for the claim that in this entry "nonsense" is mentioned in an elliptical sentence of the form: " "nonsense" means ...". Yet it is definitely not used in a proposition, as $\mathrm{P}_{1}$ requires. And it would be absurd to maintain that the words printed in bold at the beginning of dictionary entries are meaningless, all the more so since the text that follows specifies what they mean. The words on a list or the explananda in a dictionary are not used in a complete sentence, yet nonetheless meaningful. This point was anticipated by Aristotle: words in isolation "are neither true nor false", yet they nonetheless "signify something" (De Interpretatione 16a). There is a difference between a word having a meaning and a sentence being used to say something.

These objections cannot be defused by invoking the distinction between type and token. Not only is it obvious that, for example, the type "to awake" has a meaning in English, it is equally obvious that the particular token printed above is a meaningful word of English, rather than a mere scribble or collage of letters, even though it occurs on its own, outside the context of a proposition.

Its popularity notwithstanding, the restrictive context principle $\mathrm{P}_{1}$ rests on two definite (though by no means egregious) mistakes. First, it confuses actuality and potentiality. To have a meaning, a word must only be capable of occurring in a sentence (of being used to perform a speech-act), it needn't actually occur in a sentence (actually be used). ${ }^{6}$ Secondly, the restrictive context principle ignores an important feature of the established uses of "meaning" and "use". In both ordinary parlance and linguistics, we ascribe meaning primarily, though not exclusively, to words. Dictionary definitions, the very paradigm of explanations of meaning, paraphrase words or phrases rather than sentences. This is no coincidence. Far from being the "primary vehicle of meaning" or the "units of significance", as restrictive contextualists have it, most sentences are complex signs. Their meaning depends on the meaning of their constituents (Dummett 1981, pp. 3, 593; cp. Quine 1980, pp. 38-39; Diamond 1991, pp. 108-111). By and large, we master sentences by learning how to construct them from familiar words. ${ }^{7}$ Furthermore, understanding the components and mode of composition of a sentence is a necessary condition for a genuine understanding of the whole sentence, even if, as the later Wittgenstein argued, it is not always sufficient (see 1967, §§350-351).

In spite of the impression conveyed by many advocates of the austere conception, one needn't reify "meanings" to resist restrictive contextualism. Au contraire, the latter runs counter to the use-oriented perspective of meaning that they purport to accept. The meaning of a word is determined by its use, or by the rules for its correct use. Whether a sign is meaningful depends on whether there is an established use, whether it can be employed to perform meaningful linguistic acts; and what meaning it has depends on how it can be used. For us, the crucial point is this: for the most part, it is individual words and phrases rather than whole sentences that

\footnotetext{
${ }^{6}$ By dint of its venerable pedigree, persistence and pervasiveness, this confusion can lay claim to the title "the mother of all philosophical errors".

7 A threat of circularity looms here, if familiarity with words presupposes the capacity to employ them in sentences. In fact, however, children are become familiar with certain words through training involving simply speech acts like labelling or one-word sentences. This provides the foundation for the ability to employ these words in more complex speech acts.
} 
have a rule-governed use in a language. By parity of reason, the meaning of whole sentences does not consist in their use. The same moral emerges from Wittgenstein's dictum "The meaning of a word is what is explained by the explanation of meaning" (1967, §560). As Tractatus 4.026 already recognized, we typically explain the use of individual words or phrases rather than of whole sentences.

One kernel of truth in contextualism is that the meaning of a word is determined by how it can be used within sentences. ${ }^{8}$ But it does not follow that the word has meaning only in the context of a sentence. If it is clear what role tokens of a typeword would play in a sentence, tokens of that type have a meaning, whether or not they actually fulfil that role. There is a difference between having a use in the language and being actually used on a particular occasion.

Such a weak contextualism is plausible; yet it does not rule out combinatorial nonsense, i.e. does not support C. Certain grammatically well-formed strings are nonsense because of what their components mean, i.e. of how they are standardly used and explained. Thus (15) is incompatible with the combination of

\section{"Julius Caesar" is the name of a Roman general}

and

"is a prime number" is a predicate that applies to any number that can be divided only by 1 and by itself.

(21) and (22) are standard explanations of their respective explananda, and in current use, these explananda are not ambiguous. The explanations imply that the referent of "Julius Caesar" is not within the range of meaningful application of "is a prime number". That is to say, regarding (15) as meaningful is a criterion for disregarding or not understanding these explanations. By the same token, even in a combination that makes no sense overall like (15), the term "prime number" is meaningful, since there are rules for its employment in a combination that does, e.g. in

The number of apostles is prime.

It is just that these rules preclude meaningful application of the term to a person.

Bronzo attempts to block this line of reasoning. He proposes a "semantic disjunctivism": "either words are used in a meaningful way by being employed for the expression of meaningful propositions [as in (23)], or they are not used in a meaningful way at all [as in (15)]" (2011, p. 101) Even if such a strict dichotomy is tenable, however, it will not provide succour to the austere view. That "prime number" is not actually used in a meaningful way in the specific context of (15) is no obstacle to it having such a use in sentential contexts like (23), and hence to its

\footnotetext{
${ }^{8}$ Another kernel of truth is that in the case of ambiguous words, context is needed to determine which of the different meanings is at issue. But first, even such words have their different meanings outside of a sentential context, e.g. in a list of homonyms. And secondly, disambiguation does not always require the context of a complete sentence. To exclude the meaning harbour, for instance, "a bottle of port" will do just fine.
} 
having a meaning, even when it occurs in a string that makes no sense overall. That is why competent speakers confronted with (15) can explain-normally in nontheoretical terms-not just what "prime number" means, but also why it is misplaced in its current context. Contrary to the austere view (Conant 2001, pp. 13, 23), nonsense can result from "specifiable infringements" of linguistic rules.

Bronzo suspects weak contextualists of harbouring reductionist motivations by seeking a bottom-up explanation of sentences from sub-sentential building blocks and by "factorizing" our linguistic capacity: on the one hand we have knowledge of the meaning of words, on the other we have knowledge of how to employ them in sentences with a sense (2011, p. 101). Both charges are unfounded. Weak contextualism insists that to understand a word genuinely (e.g. not just by dint of knowing the meaning of a single expression from an otherwise unfamiliar tongue) requires knowing how to employ it in different types of sentences. That is why the Fodorian charge that a "use theory" cannot account for compositionality fails. What is correct about factorizing is that understanding the meaning of the words of a language is compatible with lacking certain other linguistic capacities, e.g. syntactic capacities concerning niceties of flexion.

\section{Nonsense and Privation}

It has emerged that $\mathrm{C}$ cannot be vindicated by appeal to contextualism. But perhaps it can be defended on other grounds. One might concede that "Socrates" might have a meaning outside the context of a meaningful sentence, while insisting that it lacks meaning when it occurs within the context of a nonsensical sentence like (14). In fact, however, this rejoinder is at odds with the austere account. If in (14) "Socrates" is meaningless not because we have failed to assign a meaning to it but because of its context, then its lack of meaning is not just a matter of privation, it is a matter of being in inappropriate company, just as the combinatorial view has it.

Furthermore, the claim that "Socrates" lacks meaning in (14) is implausible. One can establish who "Socrates" stands for by consulting an encyclopaedia and heeding the context of utterance (are we talking about Athenian philosophers, Byzantine theologians, Portuguese politicians or Brazilian footballers, for instance). And one can establish what the term "identical" means by consulting a dictionary (Hacker 2003 , pp. 10, 20). One can also translate (in the case of "identical") or transpose (in the case of "Socrates") the constituents of (14) into another language. Consequently, there is no obstacle to both individual expressions meaning the same in (14) as in

Socrates is identical with the husband of Xanthippe.

Of course, on some occasions words are used with a meaning that differs from their established one. In that case, their literal meaning will differ from their speaker's meaning, their meaning on occasion of utterance. That meaning is to be gleaned from the speaker's explanations. For instance, if someone utters (14), and explains "identical" as meaning human, that is what she means by it. And then her utterance of (24) would be nonsensical, because of the meaning she has 
given to "identical". By contrast to the mental associations mentioned in Sect. 1, the explanations speakers give of their words cannot be discarded as being of merely psychological importance (cp. Diamond 1991, pp. 99, 106). What a speaker means by a word in a specific utterance is not determined by what words or images happen to cross her mind; but it is determined by how the speaker would or could explain her utterance when challenged (Glock/Preston 1995).

$\mathrm{C}$ entails that all components of (14) are totally and equally bereft of meaning. But when we consider how we would react to an utterance of (14), we reach a different conclusion. Our first response would be to treat it as an incomplete sentence. We would be liable to ask "Identical with whom?", precisely because "is identical" is not a meaningless sign, but part of a two-place predicate. Imagine that our interlocutor responds by insisting "Not identical with anybody; he is just identical period!". Being philosophers, we might then suspect that by "identical" he means self-identical. If he denied this, however, we would be at a loss. The trouble with (14) concerns "identical" rather than "Socrates". No substitution for "Socrates" would render (14) meaningful, given the literal meaning of "identical". By contrast, replacing "identical" by any number of one-place predicates restores sense. It is "identical" rather than "Socrates" that is being misused in (14), and it is the combination of "identical" with "Socrates is" that makes for nonsense.

But isn't at least the privation thesis plausible on independent grounds? After all, for any allegedly nonsensical string of signs $*$ s, we could assign a sense to it such that the whole string would make sense (see Dain 2008, p. 109). Something like this thought fuels Wittgenstein's claim that if a combination of signs has no sense "that can only be because we have failed to give a meaning to some of its constituents" (1922, 5.4733). Nevertheless the appearance of plausibility is deceptive. To be sure, one can "assign" or "attach" a sense to an illicit combination of words *s, indeed any sense one pleases, namely through stipulating that it is to have a certain sense from now on. But that is not the same as *s making sense to begin with. The defence of the privation view confuses a second-with a first-order possibility. As it stands, *s cannot be used to perform a meaningful speech act. This absence of a first order possibility is precisely what its lack of sense amounts to. That $*_{s}$ could be given a sense-i.e. turned from a sign into a symbol—is a second order possibility-which is obviously immaterial to the question of whether it has a sense.

Furthermore, that we could assign a sense to a hitherto senseless string of words does not mean that our failure to do so vis-à-vis *s is the only way in which *s could fail to make sense. By the same token, one could argue that the only way in which an act could be illegal would be the failure of the executive to introduce emergence laws making it (retrospectively) legal. Or, to bring the analogy closer to our concern with compositional nonsense, one could argue that the only way in which a combination of separate provisions in a piece of legislation could fail to be compatible with a constitution would be failure of the legislative to declare the package as a whole constitutional. Both conclusions are obviously absurd, and so is the view that only failure to stipulate a sense for the whole can leave a linguistic combination bereft of sense. Finally, although there is in principle no limit to stipulating ab novo a sense for a combination of signs, two problems remain. First, attaching a sense to whole sentences through stipulation is a feature of signalling 
codes as opposed to natural languages with a compositional structure. Secondly, such stipulations must satisfy the requirement of cohering with other aspects of linguistic use, the stipulator's included.

Once we take to heart the shortcomings of strong contextualism, the distinction between literal and speaker's meaning, and the difference between first- and secondorder possibilities, the insistence that lack of sense is always the result of privation is either false or trivial. It is false if it means that none of the components of (14), for instance, have a literal meaning, and the same meaning as in meaningful combinations, or that the nonsensicality of (14) cannot result from combining "identical" with "Socrates is". It is trivial and inconsequential if it means that we could always give a meaning to any combination of words, by assigning a new meaning to one or more of its constituents, or to the combination as a whole.

\section{The No Nonsense Position and Compositionalism}

The idea that certain combinations of meaningful words, in particular category mistakes, are nonsensical has also been attacked by what one might call the no nonsense position. That view is associated with Quine's repudiation of the distinction between analytic and synthetic propositions. In so far as the former either record or determine what an expression means, combinations that run counter to them run counter to the meaning of words or to concepts rather than to facts and hence would appear to be nonsensical rather than merely false. But if the very distinction between conceptual and factual propositions were untenable, this would also undermine the dichotomy between sentences that are nonsensical and those that are merely false. Elsewhere (Glock 2003, ch. 3) I have defended these distinctions against Quine's attack. But the no nonsense position has also been advanced on independent grounds, some of which will be discussed in the sequel.

One line of criticism has been that category mistakes must be meaningful because they have a truth-value (namely false) (e.g. Haack 1971). Yet this obviously begs the question, since having a truth-value presupposes being meaningful (Routley 1969). More recent defences of the no nonsense view avoid this circular reasoning (Camp 2004; Magidor 2010). One set of arguments appeals to compositionality. ${ }^{9}$ The guiding idea is in effect the contraposition of the austere conception. Whereas the latter argues that a combination of signs can fail to have a sense only if one of its components lacks meaning, the no nonsense position maintains that a combination of meaningful components must itself have a sense. By these lights, since category mistakes consist of meaningful components, they must be meaningful. Principles of compositionality are widely brandished in contemporary formal semantics. But they have been challenged precisely by those recognizing the possibility of combinatorial nonsense like Wittgenstein and Ryle. Still, Magidor (2010, p. 557) propounds a compositionalist principle which in her view does not to beg any questions in favour of the no nonsense view.

\footnotetext{
9 Several of the combinatorial principles invoked are closely related to Evans' "generality constraint". Ironically, Evans himself specifically excluded category mistakes from the scope of that constraint (1982, p. 101n).
} 
$\left(\mathrm{CP}_{1}\right)$ If $\mathrm{S}$ is a generally competent speaker of $\mathrm{L}$ and $\mathrm{S}$ understands the terms "a" and " $\mathrm{F}$ " of $\mathrm{L}$, then $\mathrm{S}$ understands the sentence "Fa", if this is a meaningful sentence of $L$.

However, this principle implies only that the sense of senseful sentences is always a function of the meanings of its constituents and their mode of combination, not that the meanings of sentence components can always be combined to compose sentences with a sense. For this reason, it does not appear to preclude combinatorial nonsense.

At this juncture Magidor complains that combinatorial nonsense can be reconciled with $\left(\mathrm{CP}_{1}\right)$ only if one can provide a semantic framework to explain both why certain combinations make sense and why other combinations do not. She rejects what she regards as the most promising attempt to discharge this obligation, namely appealing to type-theoretic semantics. But irrespective of the potential of that specific branch of formal semantics for solving the problem, there is no general difficulty here. Among the rules that are partly constitutive of the meaning of a word "a", there will be rules that specify the combinatorial possibilities of "a" —an idea implicit in the notion of logical syntax developed by the early Wittgenstein and the middle Carnap. Alternatively, the rules at issue may imply such combinatorial exclusions, such that understanding these rules, and hence the meaning of "a", is incompatible with making sense of the combination "Fa". Allowing for this second possibility avoids a problematic implication, namely that the numerous principles of combinatorial possibilities and impossibilities are all part of the explanation of words. Verificationism is a theory of meaning that affords this second option: rules about identifying the object to which "a" refers and about deciding whether " $F$ " applies to an object are constitutive of the meaning of the respective words. And it follows from these rules that "Fa" makes no sense. An abstract object like a number that is identified through its position in a formal series defies application of a rule of classification based on assigning visible properties to spatio-temporal objects.

By this token, the proper formulation of a compositional principle should rather be

$\left(\mathrm{CP}_{2}\right)$ If $\mathrm{S}$ is a generally competent speaker of $\mathrm{L}$ and $\mathrm{S}$ understands the terms " $\mathrm{a}$ " and "F" of $\mathrm{L}$, then $\mathrm{S}$ will know whether "Fa", is a meaningful typesentence of $\mathrm{L}$, and if it is, $\mathrm{S}$ will understand " $\mathrm{Fa}$ ".

Far from excluding combinatorial nonsense, however, $\left(\mathrm{CP}_{2}\right)$ explicitly takes account of it.

A more specific objection is that

That is green or

What I am thinking of is green

make sense, notwithstanding the fact that they result in category mistakes when "that" or "what I am thinking of" refer to a number (Magidor 2010, p. 561). But while these forms of words-these type-sentences-make sense, in that they can be used to say something intelligible according to extant rules, they cannot be used to say something intelligible if the purported referent is a number. This is no more 
mysterious than the fact, highlighted in Strawson's critique of Russell's theory of descriptions, that one and the same form of words can be used to say something truth-apt in one kind of context, but not in another. As regards the question of nonsense in cases like (25) and (26), the crucial point is this. Some expressions can be used to refer to any kind of object that is suitable as a logical subject of predication. But depending on the category of the specific object they are used to refer to on a particular occasion, certain predications will make sense while others won't. Concerning (26), although numbers and material objects belong to distinct categories if anything does, both are among the things that one can think of. This is simply a consequence of the fact that our cognitive faculties include the capacity not just of perception but also of abstract thought. Similarly for the demonstrative "that" in (25). The paradigmatic use of this demonstrative pronoun is reference to material objects. Yet its employment also encompasses deferred ostension. For instance, by pointing to a numeral or a pair, I may be referring indirectly to the number two. Nonetheless, understanding deferred ostension to abstract objects implies appreciating that the objects thus referred to are not within the range of applicability of a colour predicate, by contrast to the objects through which the deferred ostension takes place.

By dint of revolving around indexicals, the preceeding objection is linked to another argument from compositionality. It concerns not the relation between subject and predicate in simple predicative sentences but logical operators. Thus Magidor endorses

$\left(\mathrm{CP}_{3}\right)$ If "p" and " $\mathrm{q}$ " are meaningful declarative sentences, then " $\mathrm{p}$ and $\mathrm{q}$ " is a meaningful declarative sentence.

$\left(\mathrm{CP}_{3}\right)$ implies that

That is green and that is prime

is meaningful, even though (27) is a category mistake, provided that the two occurrences of "that" are co-referntial (2010, p. 563).

Yet even if $\left(\mathrm{CP}_{3}\right)$ were valid in general, the principle could not be applied to cases involving indexical expressions. A principle like

$\left(\mathrm{CP}_{4}\right)$ If "That is F" and "That is $\mathrm{G}$ " make sense, then "That is $\mathrm{F}$ and that is $\mathrm{G}$ " makes sense.

Is simply unacceptable, if $\mathrm{F}$ and $\mathrm{G}$ are categorially incompatible in the way in which "green" and "prime" are. In such cases, understanding the predicates implies recognizing that they cannot apply to one and the same thing. If Magidor's argument were sound, one might as well reason that since "This cake is edible" makes perfectly good sense its extension by "and so is the number 2" must as well (here you have not anaphoric reference but something like anaphoric predication). While Magidor would accept this consequence, a proponent of the possibility of combinatorial nonsense has no reason to do so, and I reckon that competent speakers without axes to grind would concur. 


\section{Translation, Propositional Attitudes and Metaphor}

Not all objections to combinatorial nonsense rest directly on compositionalist assumptions. One line of criticism appeals to the fact that category mistakes can be translated (Magidor 2010, pp. 565-566). Since translation is supposed to preserve synonymy, the argument continues, category mistakes must be meaningful. However, delivering a meaningful sentence is a legitimate demand on translation only in cases in which the whole target string has sense to begin with. In other cases, the operative condition is simply that translation should preserve as much as feasible the meaning of sentence components and the mode of combination. In fact, yielding a meaningful sentence as translation of a string that lacks sense overall is a sufficient condition of mistranslation. Once again, rejecting these two points not only begs the question against the idea of combinatorial nonsense, it is inherently implausible.

A fourth line of criticism appeals to "propositional attitude ascriptions" (Magidor 2010, pp. 566-571). Consider sentences like

(28) Jane said that the theory of relativity is eating breakfast

(29) John believes that $\pi$ is green

(30) Sarah dreamt that her toothbrush was pregnant.

We can employ and understand these sentences. But, the argument continues, this is possible only because the embedded sentence in the indicative is meaningful as well. Once again, this is the contraposition of the austere conception. Thus Diamond (2000, pp. 151, 161) argues that, if a grammatically well-formed sentence " $p$ " is nonsense, then so is "A thinks that/says that $p$ ". Now, the no nonsense position is certainly correct in claiming that we understand indirect speech reporting category mistakes. When commentators say "Hegel wrote that the True is the Whole" or "Badiou maintains that truth is that which punctures a hole in knowledge", it is not they who talk rubbish. At the same time, the conditional by which both the austere conception and the no nonsense position set store is mistaken. The licitness of constructions like (28)-(30) does not presuppose that the embedded category mistakes are meaningful. It is simply guaranteed by the grammatical wellformedness of category mistakes. To that extent, they are part of a natural language. But what we understand in the case of (28) is to be spelled out in terms of "direct speech". It is less clear that we understand belief ascriptions like (29). In so far as we do, what we understand boils down to understanding indirect speech constructions like (28). After all, what would it be for someone to really believe that $\pi$ is green, apart from his being inclined to say thinks like " $\pi$ is green", "The ratio of the circumference of a circle and its diameter is green", etc.? Could John display his conviction by trying to repaint $\pi$, for instance? Even tentative steps in that direction-as opposed, e.g., to repaint a token-numeral—appear doomed. As for (30), in fairy-tales this can make sense, although they involve treating toothbrushes as organisms, thus removing the license for calling them inanimate artefacts and hence for condemning "Sarah's toothbrush is pregnant" as a category mistake. 
Finally, opponents of combinatorial nonsense have appealed to metaphor. Since metaphors are understood, the story goes, and since many of them involve category mistakes, the latter must make sense (Magidor 2010, pp. 571-572). However, there is a widespread and credible account of metaphors that easily blocks this line of reasoning. It is the idea that metaphors involve similes or comparisons. While "Juliet is the sun" may be unintelligible taken literally, "Juliet is like the sun (in such-and-such respects)" is anything but.

Magidor challenges advocates of a simile account to apply it to complex cases like

(31) John rides his mind at a gallop in search of an idea

Fortunately, this can be achieved by going beyond the paradigm of transforming "a is (an) F" into "A is like (an) F". (31) can be spelled out as

\section{John exercises his mind intensively, in search of an idea}

Magidor insists that that this tactic must account for the way in which the paraphrase respects the meaning not just of words, but also of complete phrases (2010, pp. 572-573). But this would not appear to be a problem. In spelling out (31) we start with "John rides", and consider the question "what?". If the answer is "his mind", we gather that it is a matter of exercising his mind, just like one can exercise a horse by riding it. The addition "at a gallop" informs us that the exercise of John's mental faculties occurs at great speed or intensity. Next, when we hear "in search of", we understand that the mind is exercised intensively for the benefit of identifying something that answers to a certain description. Finally, "an idea" tells us that this something is an idea. This gives us a clue of the kind of search or identification procedure involved, since searching for an idea is different from searching for a fox, for instance. ${ }^{10}$

\section{Semantic Mistakes and Unintelligibility (vis-à-vis Davidson)}

I now turn to a final challenge to the idea that there is a connection between nonsense resulting from semantic infelicities and unintelligibility. It arises not from an explicit interest in nonsense, but from an influential account of linguistic communication, that of Davidson. That account features two claims that are pertinent to our topic.

Anti-normativism: meaning has no essential connections with semantic rules

Individualism: the only genuine linguistic phenomenon is the idiolect-the language of an individual; shared languages are at best derived.

\footnotetext{
${ }^{10}$ Magidor denies that simile can explain metaphors to begin with. She appeals to Davidson's objection that the theory cannot do justice to the fact that metaphors are difficult to figure out and defy paraphrase in literal terms. But analogies and comparisons can be complex, rich and unserveyable. These kinds of comparisons defy straightforward paraphrase no less than ambitious metaphors do. For a convincing defence of the simile account against other objections see Schroeder 2004.
} 
Like New Wittgensteinianism, Davidson's position is at odds with the idea that linguistic communication and hence mutual intelligibility require a shared system of semantic rules and that natural languages are persistent social practices which are more than the sum of individual speakers or idiolects. Unlike the New Wittgensteinians, who pay scant attention to human communication, Davidson is explicit on this score. What is more, he offers an elaborate defence of his repudiation of shared semantic rules, to which I shall refer as conventions. ${ }^{11}$

Individualists standardly grant that we tend to speak as others do, while insisting that this is for extrinsic-non-semantic, non-linguistic reasons. Thus Davidson maintains that knowledge of shared rules is "neither necessary nor sufficient for successful linguistic communication" (1994, p. 2). According to an orthodoxy inspired by Davidson's own truth-conditional theory of meaning, communication is successful only if speaker and hearer share a truth-theory that provides a recursive characterization of the truth-conditions of all potential utterances of a natural language L. Speaker and hearer approach each occasion of utterance armed with such a theory, and both assume that such a theory is shared by others, and assumed to be shared.

Davidson claims that this account cannot make sense of the fact that malapropisms, spoonerisms and similar infelicities are not only common, but also commonly understood (1986, pp. 436, 440-441). In the appropriate circumstances, we have no difficulty in interpreting Mrs Malaprop's remark "A nice derangement of epitaphs" as meaning "a nice arrangement of epithets". However, no antecedent truth-theory for English could deliver in advance a T-sentence like

"This is a nice derangement of epitaphs" is true if this is a nice arrangement of epithets.

We understand Mrs Malaprop, although her truth-theory differs from ours. Therefore mutual understanding does not require that speakers and hearers share a truth-theory in advance of specific speech acts.

Each speaker may speak his different language, and this will not hinder communication as long as each hearer understands the one who speaks.... Communication does not demand, then, that speaker and hearer mean the same thing by the same words (1984, pp. 276-277).

What it demands instead is a "fit between how speakers intend to be interpreted and how their interpreters understand them" (1990, p. 311).

Davidson's own explanation of how such fit is achieved runs as follows (1984, pp. 277-278; 1986, pp. 441-442). We approach each communicative situation with what he calls a "prior theory". But the individual members of a linguistic community differ substantially in their dispositions to verbal behaviour. As a result, speakers constantly have to react to unexpected uses by passing from their prior theory to a "passing theory", an ad-hoc explanatory hypothesis which reinterprets any utterance in the light of the principle of charity.

11 Glock 2010 provides a more sustained critique of Davidson's position. 
For the hearer, the prior theory expresses how he is prepared in advance to interpret an utterance of the speaker, while the passing theory is how he does interpret the utterance. For the speaker, the prior theory is what he believes the interpreter's prior theory to be, while his passing theory is the one he intends the interpreter to use (1986, p. 442).

Neither prior nor passing theory amount to a body of conventions which speaker and hearer use to communicate. The passing theory is shared between speaker and hearer, but it does not correspond to an interpreter's general linguistic competence, since "knowing a passing theory is only knowing how to interpret a particular utterance on a particular occasion" (1986, p. 443). The prior theory, on the other hand, to some extent equips us to deal with a variety of speakers and situations. But it is neither shared between speaker and hearer, nor does it correspond to what we ordinarily think of as a natural language, since it contains many idiosyncratic features. For each speaker will constantly adapt his prior theory in the light of previous linguistic exchanges.

Davidson is right to think that malapropisms, spoonerisms and similar foibles pose a threat to the orthodox account. He is also right to claim that in the rough-andtumble of everyday communication we often rely both on context-specific knowledge (e.g. concerning the speaker and the circumstances of utterance) and on "shared general information and familiarity with non-linguistic institutions ('a way of life')" (1994, p. 10). This is an important fact, since it casts doubt on strong versions of compositionalism like the ones invoked by the no nonsense faction. Strong compositionalism holds that for an understanding of sentences it is not just necessary but also sufficient to understand its components and their mode of composition. If Davidson draws the right moral from malapropisms, however, knowledge of components and mode of composition is neither necessary nor sufficient for understanding the utterance of a sentence in a specific context. In my view he is wrong about the first point, right about the second.

Davidson is also right in holding that communication can succeed between people employing different languages. At certain stages of their development, bilingual children often employ only one language, even when spoken to in another. What is more interesting is that communication can succeed between individuals who do not share a language, even passively. In interactions with foreigners, we sometimes communicate by way of facial expressions, gestures and through intonation. The moot question is whether there is "communication by language" without semantic conventions, as Davidson maintains (1984, p. 265).

He supports this claim by considering malapropisms. When these are understood, it clearly amounts to linguistic communication. The question is, however, whether such understanding does not rely on a background of shared conventions after all. For one thing, from the fact that people can deviate sometimes, it does not follow that they could always deviate. It is difficult to see how we might all be constantly committing malapropisms, without communication breaking down. For another, even isolated malapropisms do not support Davidson's case. We are often, albeit by no means always, capable of understanding linguistic infelicities, but only because they are recognizable and in some way, intelligible deviations from a shared norm. We would not understand Mrs Malaprop if she said, for example, "a gwackne uldmob of 
delgolph". Admittedly, that would not qualify as a malapropism. But the point is precisely that the latter can be understood precisely because, by definition, they differ from correct utterances by violating specific rules in ways that competent speakers can identify. Therefore their intelligibility does not support the conclusion that understanding can do without conventins. Finally, malapropisms show that uttering semantic infelicities does not always preclude being understood. But in these fortunate cases, what we understand is what speakers meant to say (what was meant), not what they actually said, the literal, conventional meaning (what was said).

\section{Unintelligibility and Literal Meaning}

One problem in driving home this point is that Davidson and his followers often employ standards of intelligibility that I find difficult to comprehend. Thus Davidson assures us that "we do not understand" sentences like

The proposition that Caesar was murdered is true if and only if Caesar was murdered (1999, pp. 108-109).

At the same time, he finds "most of "The Jabberwocky"... intelligible on first hearing" (1986, p. 434). I profess to the opposite inclination. To be sure, we can easily associate The Jabberwocky with certain images. But we are not in a position to explain what terms like "brillig", "slithy" or "tove" mean. I am at a slightly less severe loss with the following statement by an NFL head coach unearthed by LePore and Ludwig: "We know that if we've got our head between our tails, we can get embarrassed very quickly". ${ }^{12}$ I get the rough gist of what the coach meant to say: if a team commits some kind of mistake, it will be liable to suffer an embarrassing defeat. Yet I am simply ignorant of what it means for a group of football players to have their heads between their tails. Understanding of malapropisms is pretty much guaranteed only in cases in which we are dealing with a clear variant of a single established idiom, and such understanding is clearly parasitic on the standard use.

Davidson suggests that shared normative ingredients of language, even if real, have nothing to do with meaning. In fact, however, they have everything to do with literal meaning. What they do not concern is speaker's meaning. In his attack on conventions Davidson runs the two together (see Dummett 1986, p. 473; Hacker 1997, pp. 295-299). Thus he accuses Dummett's claim that words have a meaning independently of individual speakers of invoking "an elitist norm by implying that people not in the right social swim don't really know what they mean" (1994, p. 12). Proponents of linguistic conventions have never suggested that speakers might be ignorant of what they mean by their words, in the sense of knowing what they meant to say, but rather that they might be ignorant of what these words mean, or of what they actually said.

\footnotetext{
12 In a manuscript of 2002, p. 3, they claim that "we have no trouble understanding what he meant to convey". However, they do not repeat either this wonderful example nor their assessment in the published version (2007).
} 
Davidson's charge is based on an explicit identification of these two notions. He writes:

An utterance has certain truth-conditions only if the speaker intends it to be interpreted as having those truth-conditions.... A malapropism or slip of the tongue, if it means anything, means what its promulgator intends it to mean (1990, p. 310).

But although Mrs. Malaprop may have intended to use a phrase meaning a nice arrangement of epithets, this is not what the phrase she actually used means. Davidson's position provokes the charge that he adheres to a Humpty-Dumpty theory of meaning. Anticipating this charge, he wrote:

Humpty-Dumpty is out of it. He cannot mean what he says he means because he knows that "There's glory for you" cannot be interpreted by Alice as meaning "There's a nice knockdown argument for you" (1986, p. 440).

It is only subject to constraints of interpretability that "what a speakers words mean" is "what he intends them to mean". He must have provided sufficient "clues" to be understood (2001, pp. 13-4, 28).

Unfortunately, one cannot avoid Humpty-Dumpty semantics simply by meaning to do so. No matter how many clues a speaker drops, what her utterance literally means can differ from how she intends it to be understood. This is simply part and parcel of the notion of literal meaning. Ultimately, Davidson's individualism joins hands with the austere conception of nonsense and the no nonsense position in repudiating the idea that because of their literal meaning, words can be intelligibly combined in some ways but not others. If my criticisms are along the right lines, this triple alliance is an unholy one.

Acknowledgments For comments on previous versions, I am indebted to Alex Burri, Peter Hacker, as well as to audiences at Regensburg and Erfurt. I am particularly grateful to Kai Büttner and David Dolby for alerting me to complications concerning the passive nature of understanding and the connection between the privation view of nonsense and nonsense monism.

\section{References}

Baker, G. P., \& Hacker, P. M. S. (2005). Wittgenstein: Understanding and meaning, part I: Essays. Oxford: Blackwell.

Bronzo, S. (2011). Context, compositionality, and nonsense in Wittgenstein's Tractatus. In R. Read \& M. Lavery (Eds.), Beyond the Tractatus Wars (pp. 84-111). New York: Routledge.

Camp, E. (2004). The generality constraint and categorical restrictions. Philosophical Quarterly, 54, 210-231.

Chomsky, N. (1957). Syntactic structures. The Hague: Mouton.

Chomsky, N. (1965). Aspects of the theory of syntax. Cambridge, MA: MIT Press.

Conant, J. (2001). Two Conceptions of Die Überwinding der Metaphysik. In T. McCarthy \& S.C. Stidd (Eds.), Wittgenstein in America (pp. 13-61). New York: Oxford University Press.

Conant, J. (2002). The method of the Tractatus. In E. Reck (Ed.), From Frege to Wittgenstein (pp. 374-470). Oxford: Oxford University Press.

Creary, A., \& Read, R. (Eds.). (2000). The New Wittgenstein. London: Routledge.

Dain, E. (2008). Wittgenstein, contextualism and nonsense: A reply to Hans-Johann Glock. Journal of Philosophical Research, 33, 111-125. 
Davidson, D. (1984). Inquiries into truth and interpretation. Oxford: Oxford University Press.

Davidson, D. (1986). A nice derangement of epitaphs. In E. LePore (Ed.), Truth and interpretation (pp. 433-446). Oxford: Blackwell.

Davidson, D. (1990). The structure and content of truth. Journal of Philosophy, 87, 279-328.

Davidson, D. (1994). The social aspect of language. In B. McGuinness \& G. Oliveri (Eds.), The philosophy of Michael Dummett (pp. 1-16). Dordrecht: Kluwer.

Davidson, D. (1999). The centrality of truth. In J. Peregrin (Ed.), Truth and its nature (if any) (pp. 105-115). Dordrecht: Kluwer.

Davidson, D. (2001). Subjective, intersubjective, objective. Oxford: Oxford University Press.

Diamond, C. (1991). The realistic spirit. Cambridge, MA: MIT Press.

Diamond, C. (2000). Ethics, imagination and the method of Wittgenstein's Tractatus. In A. Creary \& R. Read (Eds.), The new Wittgenstein (pp. 149-173). London: Routledge.

Dummett, M. (1981). Frege: Philosophy of language. London: Duckworth.

Dummett, M. (1986). A nice derangement of epitaphs: Some comments on Davidson and Hacking. In E. LePore (Ed.), Truth and interpretation: Perspectives on the philosophy of Donald Davidson (pp. 459-476). Oxford: Blackwell.

Dummett, M. (1991). Frege and other philosophers. Oxford: Clarendon.

Evans, G. (1982). The varieties of reference. Oxford: Oxford University Press.

Glock, H. J. (1996). A Wittgenstein dictionary. Oxford: Blackwell.

Glock, H. J. (2003). Quine and Davidson on thought, language and reality. Cambridge: Cambridge University Press.

Glock, H. J. (2004). All kinds of nonsense. In E. Ammereller \& E. Fischer (Eds.), Wittgenstein at work (pp. 221-245). London: Routledge.

Glock, H. J. (2008). Necessity and language: In defence of conventionalism. Philosophical Investigations, $31,24-47$.

Glock, H. J. (2010). Does language require conventions? In P. Frascolla, D. Marconi, \& A. Voltolini (Eds.), Wittgenstein: Mind, meaning and metaphilosophy (pp. 85-112). London: Palgrave.

Glock, H. J., \& Preston, J. (1995). Externalism and first person authority. The Monist, 78, 515-534.

Haack, R. J. (1971). No need for nonsense. Australasian Journal of Philosophy, 49, 71-77.

Hacker, P. M. S. (1997). Davidson on first-person authority. Philosophical Quarterly, 47, 285-304.

Hacker, P. M. S. (2003). Wittgenstein, Carnap and the New American Wittgensteinians. The Philosophical Quarterly, 53, 1-23.

Hacker, P. M. S. (2006). Human nature: The categorical framework. Oxford: Blackwell.

Kenny, A. J. P. (1989). The metaphysics of mind. Oxford: Oxford University Press.

Künne, W. (1983). Abstrakte Gegenstände. Frankfurt: Suhrkamp.

Lepore, E., \& Ludwig, K. (2002). The reality of language, unpublished manuscript.

Lepore, E., \& Ludwig, K. (2007). The Reality of Language: on the Davidson/Dummett exchange. In R. E. Auxier \& L. E. Hahn (Eds.), The philosophy of Michael Dummett (pp. 185-214). LaSalle: Open Court.

Magidor, O. (2010). Category mistakes are meaningful. Linguistics and Philosophy, 32, 553-581.

Moore, G. E. (1903). Principia ethica. Cambridge: Cambridge University Press.

Quine, W. V. (1980). From a logical point of view. Cambridge, MA: Harvard University Press.

Routley, R. (1969). The need for nonsense. Australasian Journal of Philosophy, 44, 172-209.

Rundle, B. (2001). Meaning and understanding. In H. J. Glock (Ed.), Wittgenstein: A critical reader (pp. 94-118). Oxford: Blackwell.

Ryle, G. (1949). The concept of mind. repr. London: Penguin.

Ryle, G. (1970). Autobiographical. In O. P. Wood \& G. Pitcher (Eds.), Ryle (pp. 1-15). London: Macmillan.

Ryle, G. (1971). Collected papers 2. London: Hutchinson.

Schroeder, S. (2004). Why Juliet is the Sun. In M. Siebel \& M. Textor (Eds.), Semantik und Ontologie (pp. 63-101). Frankfurt: Ontos.

Waismann, L. (1965). The principles of linguistic philosophy. London: Macmillan.

Wittgenstein, L. (1922). Tractatus logico-philosophicus. London: Routledge \& Kegan Paul.

Wittgenstein, L. (1967). Philosophical investigations. Oxford: Blackwell.

Wittgenstein, L. (1993). Philosophical occasions. In J. Klagge, \& A. Nordmann (Eds.), Indianapolis: Hackett. 